\title{
Detection of AmpC $\beta$ Lactamases in Gram-negative Bacteria
}

\section{Gunjan Gupta, Vibhor Tak, Purva Mathur}

Department of Laboratory Medicine, Jai Prakash Narain Apex Trauma Centre, All India Institute of Medical Sciences, New Delhi, India

Address for correspondence: Dr. Purva Mathur, E-mail: purvamathur@yahoo.co.in

\section{ABSTRACT}

AmpC $\beta$-lactamases are clinically important cephalosporinases encoded on the chromosomes of many Enterobacteriaceae and a few other organisms, where they mediate resistance to cephalothin, cefazolin, cefoxitin, most penicillins, and $\beta$-lactamase inhibitor/ $\beta$-lactam combinations. The increase in antibiotic resistance among Gram-negative bacteria is a notable example of how bacteria can procure, maintain and express new genetic information that can confer resistance to one or several antibiotics. Detection of organisms producing these enzymes can be difficult, because their presence does not always produce a resistant phenotype on conventional disc diffusion or automated susceptibility testing methods. These enzymes are often associated with potentially fatal laboratory reports of false susceptibility to $\beta$-lactams phenotypically. With the world-wide increase in the occurrence, types and rate of dissemination of these enzymes, their early detection is critical. AmpC $\beta$-lactamases show tremendous variation in geographic distribution. Thus, their accurate detection and characterization are important from epidemiological, clinical, laboratory, and infection control point of view. This document describes the methods for detection for AmpC $\beta$-lactamases, which can be adopted by routine diagnostic laboratories.

Key words: AmpC $\beta$-lactamases, disk approximation test, gram-negative bacteria, three-dimensional extract test

\section{INTRODUCTION}

rug resistance poses a therapeutic problem not only in the hospital settings, but also in the community as most of the bacteria have acquired resistance to multiple antibiotics. $^{[1,2]}$ The various mechanisms of drug resistance in Gram-negative bacteria include extended spectrum beta-lactamases (ESBL) production, $A m p C$ $\beta$-lactamase production, efflux mechanism and porin deficiency. In the clinical laboratory settings, the commonly detected enzymes causing resistance are $A m p C \beta$-lactamases and ESBLs. Clinical relevance of $A m p C \beta$-lactamases lies in the fact that they confer resistance to both narrow and broad spectrum cephalosporins, beta-lactam/beta-lactamase inhibitor combinations and aztreonam. ${ }^{[3]}$

\begin{tabular}{|l|l|}
\hline \multicolumn{2}{|c|}{ Access this article online } \\
\hline Quick Response Code: & Website: \\
\hline & \\
\hline
\end{tabular}

AmpC $\beta$-lactamases can be chromosomally or plasmid mediated. The plasmid mediated $A m p C \beta$-lactamases hydrolyze all $\beta$-lactam antibiotics except cefepime and carbapenems. The plasmid-mediated $A m p \mathrm{C}$ genes are derived from inducible chromosomal genes that have been mobilized among various organisms. The commonly reported genotypes are ACC, FOX, MOX, DHA, CMY, CIT and EBC. ${ }^{[4-6]}$ These mobilized plasmid mediated enzymes confer a resistance pattern similar to the overproduction of chromosomal $A m p C \beta$-lactamases, which also involve all $\beta$-lactam antibiotics except for carbapenems and cefepime. ${ }^{[7]}$

Detection of $A m p C$ is important to improve the clinical management of patients suffering from infections and would also provide us with sound epidemiological data. However, there are no Clinical and Laboratory Standards Institute guidelines for detection of $A m p C$ mediated resistance in Gram-negative clinical isolates and hence, it usually poses a problem due to misleading results, especially so in phenotypic tests. ${ }^{[8]}$ 


\section{Personnel qualifications}

The test performer should be having a diploma in laboratory technologies and preferably university graduate in biological sciences with sufficient experience.

\section{Education and training}

Personnel are required to be knowledgeable of the procedures in the microbiology laboratory. The laboratory staff should confirm that they can properly perform the procedures before commencing work. The details are given in Table 1.

\section{PROCEDURE}

Techniques to identify AmpC $\beta$-lactamase-producing isolates are available but are still evolving and are not

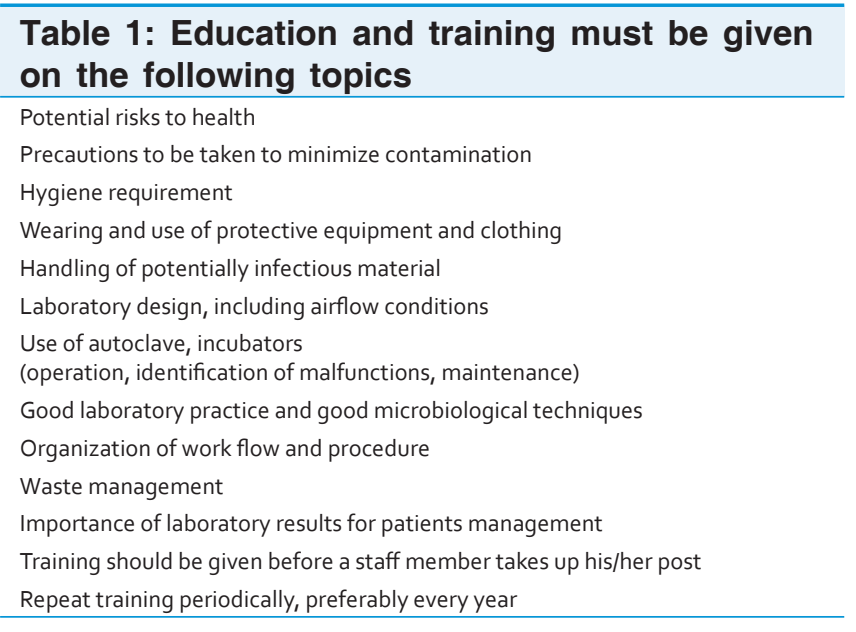

yet optimized for the clinical laboratory, which leads to the underestimation of these resistance mechanisms. Carbapenems can usually be used to treat infections due to $A m p C$-producing bacteria, but carbapenem resistance can arise in some organisms by mutations that reduce influx (outer membrane porin loss) or enhance efflux (efflux pump activation).

\section{REQUIREMENTS}

The list of all the requirements are given in Table 2.

Isolates

Gram-negative bacterial isolates recovered from clinical samples.

Preparation of reagents and chemicals

1. $300 \mu \mathrm{g}$ phenylboronic acid

- Weigh 150 mg phenylboronic acid and dissolve in $10 \mathrm{ml}$ sterile distilled water

- Use it as $15 \mu \mathrm{g} / \mu \mathrm{l}$ stock

- $\quad$ Store at $4^{\circ} \mathrm{C}$

2. $0.5 \mathrm{M}$ ethylenediaminetetraacetic acid (EDTA) buffer

- Weigh $18.6 \mathrm{~g}$ EDTA and add distilled water to $90 \mathrm{ml}$

- $\quad$ Adjust pH to 8.0

- $\quad$ Add distilled water and make final volume $100 \mathrm{ml}$

- $\quad$ Store at $4^{\circ} \mathrm{C}$

3. Tris-EDTA (TE) buffer

50X TE (stock solution)

\begin{tabular}{|c|c|c|c|c|c|}
\hline Equipments and materials & Media & Reagents and solutions & Antibiotic disks & ATCC strains & Other material \\
\hline Simple microscope & $\begin{array}{l}\text { Mueller-Hinton } \\
\text { agar }\end{array}$ & Normal saline & Cefoxitin disk (зо $\mu \mathrm{g})$ & E. coli ATCC 25922 & $\begin{array}{l}\text { Sterile micropipette } \\
\text { tips }\end{array}$ \\
\hline Incubator set at $37^{\circ} \mathrm{C}$ & Blood agar & Tris-EDTA & $\begin{array}{l}\text { AmpC disk (i.e., filter paper } \\
\text { disks containing Tris-EDTA) }\end{array}$ & E. coli ATCC 11775 & Sterile culture plates \\
\hline Autoclave & $\begin{array}{l}\text { MacConkey } \\
\text { agar }\end{array}$ & Phenylboronic acid & Imipenem $(10 \mu \mathrm{g})$ & $\begin{array}{l}\text { K. pneumoniae } \\
\text { ATCC BAA } 1144\end{array}$ & Sterile swabs \\
\hline Water bath & $\begin{array}{l}\text { Brain heart } \\
\text { infusion broth }\end{array}$ & DNA extraction kits & Cefoxitin $(30 \mu \mathrm{g})$ & $\begin{array}{l}\text { E. cloacae ATCC } \\
\text { BAA } 1143\end{array}$ & $\begin{array}{l}\text { Sterile microcentrifuge } \\
\text { tube }\end{array}$ \\
\hline Weighing balance & & $\begin{array}{l}\text { Molecular biology grade } \\
\text { water }\end{array}$ & $\begin{array}{l}\text { Amoxicillin-clavulanate } \\
(20 / 10 \mu \mathrm{g})\end{array}$ & & PCR tubes $(50 \mu \mathrm{l})$ \\
\hline Refrigerator/freezer & & Absolute ethanol & Ceftazidime $(30 \mu \mathrm{g})$ & & Sterile $1.5 \mathrm{ml}$ Appendorf \\
\hline \multirow{2}{*}{$\begin{array}{l}\text { Micropipettes } \\
\text { (1000 } \mu \mathrm{l}, 100 \mu \mathrm{l}, 20 \mu \mathrm{l} \text { and } 10 \mu \mathrm{l})\end{array}$} & & PCR reagents & & & Sterile storage vials \\
\hline & & Taq DNA polymerase $(5 \mathrm{U} / \mu \mathrm{l})$ & & & Forceps \\
\hline Centrifuge & & 10XTaq buffer with $\mathrm{KCL}$ & & & Parafilm \\
\hline PCR thermocycler & & Tris- $\mathrm{HCl}(\mathrm{pH} 8.4)$ & & & \\
\hline Gel electrophoresis & & $25 \mathrm{mM} \mathrm{MgCl} 2$ & & & \\
\hline \multirow[t]{3}{*}{ Gel Doc } & & DNTPS $10 \mathrm{mM}$ (fermentas) & & & \\
\hline & & Agarose & & & \\
\hline & & DNA ladder $100 \mathrm{bp}$ & & & \\
\hline
\end{tabular}

PCR: Polymerase chain reaction, EDTA: Ethylenediaminetetraacetic acid, DNA: Deoxyribonucleic acid, DNTPS: Deoxynucleotide triphosphate, ATCC: American type culture collection, KCL: Potassium chloride 
- Weigh $121 \mathrm{~g}$ Tris base and dissolve in $400 \mathrm{ml}$ distilled water

- $\quad$ Add $50 \mathrm{ml} 0.5 \mathrm{M}$ EDTA

- Add distilled water and make final volume $500 \mathrm{ml}$

- $\quad$ Store at $4^{\circ} \mathrm{C}$

4. TE buffer (working)

- Dilute 50X master stock to 1X with distilled water.

5. Primer reconstitution.

Primers are often shipped and received in a lyophilized state. First create a master 100X stock (for each primer and then dilute it to a $20 \mathrm{X}$ working stock).

Master stock, $100 \mu \mathrm{M}$

- $\quad 100 \mu \mathrm{M}=\mathrm{X}$ nmoles lyophilized primer $+(\mathrm{X} \times 10$ $\mu \mathrm{l}$ molecular grade $\mathrm{H}_{2} \mathrm{O}$ )

- To determine the amount of $\mathrm{H}_{2} \mathrm{O}$ to add to the lyophilized primer simply multiply the number of nmol of primer in the tube by 10 and that will be the amount of $\mathrm{H}_{2} \mathrm{O}$ to add to make a $100 \mu \mathrm{M}$ primer stock

- Vortex tube and incubate at room temperature for 10 min.

Working stock, $20 \mu \mathrm{M}$

- Dilute the primer master stock in a sterile microcentrifuge tube $1: 5$ with molecular grade $\mathrm{H}_{2} \mathrm{O}$.

\section{TEST PROCEDURE}

What is unnecessary?

It is unnecessary to detect $A m p \mathrm{C}$ production in organisms that produce an inducible chromosomal $A m p C \beta$-lactamase because the organism identification is indicative of AmpC production; i.e. 100\% isolates of Enterobacter cloacae, Enterobacter aerogenes, Citrobacter freundii, Serratia marcescens, Providencia sp., Morganella morganii, Hafnia alvei, Aeromonas sp., and P. aeruginosa can be assumed to be $A m p C$ producers. Detection of an $A m p C B$-lactamase in Klebsiella sp., Citrobacter koseri or Proteus mirabilis is confirmatory for plasmid-mediated $A m p C$ production because these organisms lack a chromosomal $A m p C \beta$-lactamases. ${ }^{[9,10]}$

\section{Screening}

i. Requirement

- Test organism

- Normal saline

- Blood agar plates

- Mueller-Hinton agar (MHA) plates

- 30- $\mu \mathrm{g}$ cefoxitin disk

ii. Procedure

- Make 0.5 McFarland bacterial suspension in normal saline prepared from an overnight blood agar plate

- Inoculate surface of MHA plate with this suspension by swabbing

- $\quad$ Place 30- $\mu$ g cefoxitin disk on inoculated MHA

- Invert the plate and incubate overnight at $35^{\circ} \mathrm{C}$

iii. Plate reading and interpretation

- After overnight incubation measure zone diameter around $30-\mu \mathrm{g}$ cefoxitin disk

- Select the isolates with zone diameters less than $18 \mathrm{~mm}$ for confirmation of $A m p C$ production.

Phenotypic confirmatory tests

Three-dimensional extract test

i. Requirement

- Test organism

- Eschericbia coli ATCC 25922 or E. coli ATCC 11775

- Normal saline

- Blood agar plates

- MHA plates

- $12 \mathrm{ml}$ brain heart infusion (BHI) broth

- 30- $\mu \mathrm{g}$ cefoxitin disk

- Sterile blade

ii. Procedure

- Prepare 0.5 McFarland bacterial suspension from an overnight blood agar plate

- Inoculate $12 \mathrm{ml} \mathrm{BHI}$ broth with $50 \mu \mathrm{l}$ of 0.5 $\mathrm{McF}$ arland bacterial suspension and incubate for $4 \mathrm{~h}$ at $37^{\circ} \mathrm{C}$

- Concentrate cells by centrifugation and freeze-thaw 5 times to prepare crude enzyme

- Prepare 0.5 McFarland bacterial suspension using one of two E. coli ATCC 25922 or ATCC 11775 and inoculate surface of MHA plate by using this suspension

- $\quad$ Place $30-\mu \mathrm{g}$ cefoxitin disk on the inoculated agar plate

- With a sterile scalpel blade, cut a slit beginning $5 \mathrm{~mm}$ from the edge of the disk in an outward radial direction

- By using a pipette, dispense 25-30 $\mu$ l of enzyme preparation into the slit, beginning near the disk and moving outward, avoiding slit overfill

- Incubate inoculated media overnight at $37^{\circ} \mathrm{C}$

iii. Plate reading and interpretation

- After overnight incubation check the enhanced growth of the surface organism at the point where the slit intersected

- If there is a zone of inhibition of surface organism, the test is positive three-dimensional test [Figure 1]. 


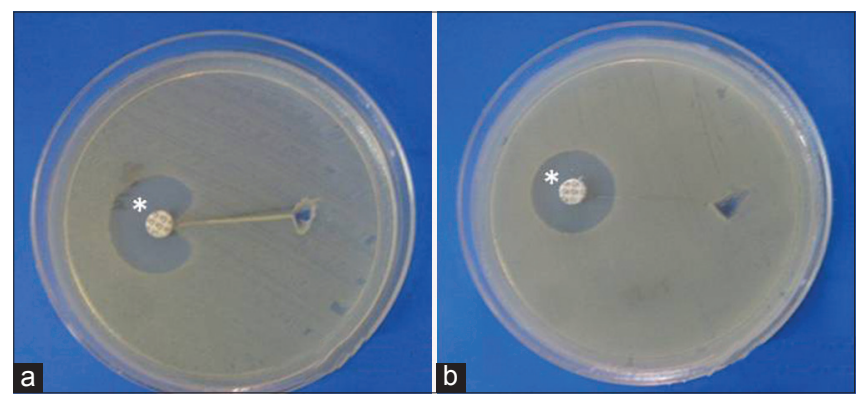

Figure 1: Representation of three dimensional extract test. (a) Zone of inhibition showing positive test, (b) no zone of inhibition showing negative test. ${ }^{*} 30 \mu \mathrm{g}$ cefoxitin disk

\section{AmpC disk test}

i. Requirements

- $\quad A m p C$ disks (filter paper disks containing TE)

- $30 \mu \mathrm{g}$ cefoxitin disk

- Blood agar plates

- MHA plates

- Test organisms

- E. coli ATCC 25922

- Normal saline

ii. Procedure

- Prepare $0.5 \mathrm{McF}$ arland bacterial suspension of E. coli ATCC 25922

- Inoculate surface of MHA plate using this suspension as per standard disk diffusion method

- Immediately prior to use, rehydrate $A m p C$ disk with $20 \mu \mathrm{l}$ of saline and several colonies of each test organism apply to a disk

- Place a $30 \mu \mathrm{g}$ cefoxitin disk on the inoculated surface of the MHA

- Place inoculated $A m p C$ disk almost touching the antibiotic disk with the inoculated disk face in contact with the agar surface

- Invert the plate and incubate overnight at $35^{\circ} \mathrm{C}$ in ambient air

iii. Plate reading and interpretation

- After overnight incubation, examine the plate for either an indentation or a flattening of the zone of inhibition

- If there is any zone of inhibition, it indicates enzymatic inactivation of cefoxitin (positive result)

- If no zone inhibition, indicates no significant inactivation of cefoxitin (negative result) [Figure 2].

\section{Boronic acid disk, test method}

i. Requirements

- Test organism

- $30 \mu \mathrm{g}$ cefoxitin disk

- Phenylboronic acid
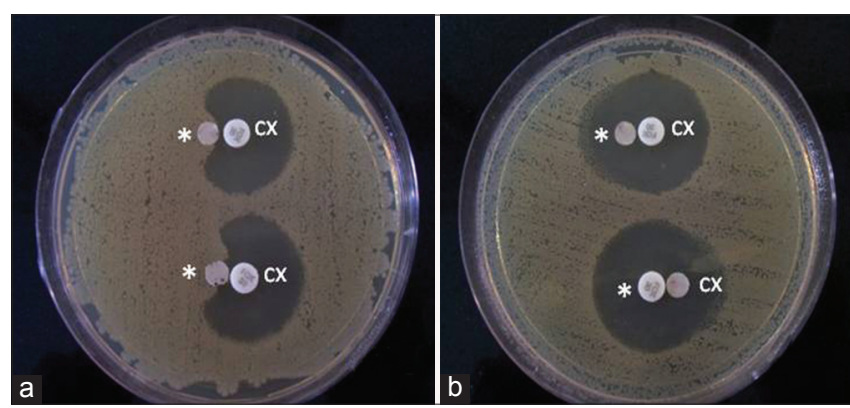

Figure 2: Representation of $A m p C$ disk test. (a) Zone of inhibition showing positive test results, (b) no zone of inhibition showing negative test results, *AmpC disks (filter paper containing tris-EDTA), CX: $30 \mu \mathrm{g}$ cefoxifin disks

- MHA plates.

ii. Procedure

- Prepare 0.5 McFarland bacterial suspension from an overnight blood agar plate

- Inoculate surface of MHA plate using this suspension as per standard disk diffusion method

- Place a $30 \mu \mathrm{g}$ cefoxitin disk on the inoculated surface of the MHA

- Using sterile tips, dispense $20 \mu \mathrm{l}$ of $15 \mu \mathrm{g} / \mathrm{ml}$ phenylboronic acid onto the disk

- Let the disk absorb it

- Invert the plate and incubate overnight at $35^{\circ} \mathrm{C}$.

iii. Plate reading and interpretation

- After overnight incubation, compare the zone diameter around the antibiotic disk with added boronic acid and the antibiotic-containing disk alone

- An organism that demonstrates a defined increase $(\geq 5-\mathrm{mm})$ in zone diameter around the antibiotic disk with added boronic acid consider to be an $A m p C$ producer [Figure 3]. ${ }^{[5]}$

\section{Disk approximation test}

i. Requirements

- Test organism

- Normal saline

- $10 \mu \mathrm{g}$ imipenem disk

- $30 \mu \mathrm{g}$ cefoxitin disk

- $20 / 10 \mu \mathrm{g}$ amoxicillin-clavulanate disk

- $30 \mu \mathrm{g}$ ceftazidime disk

- MHA Plates

ii. Procedure

- Prepare 0.5 McFarland bacterial suspension from an overnight blood agar plate

- Inoculate surface of MHA plate using this suspension as per standard disk

- diffusion method

Journal of Laboratory Physicians / Jan-Jun 2014 / Vol-6 / Issue-1 


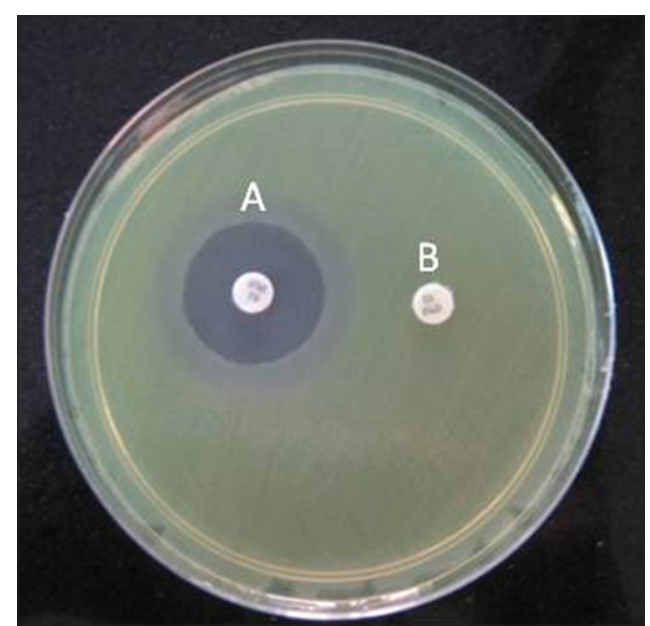

Figure 3: Representation of boronic acid disk test. A: $30 \mu \mathrm{g}$ cefoxitin disk supplemented with $300 \mu \mathrm{g}$ of phenyl boronic acid. B: $30 \mu \mathrm{g}$ cofoxitin disk alone

- Place a $30 \mu \mathrm{g}$ ceftazidime disk at the center on the plate

- Place $10 \mu \mathrm{g}$ imipenem, $30 \mu \mathrm{g}$ cefoxitin, and $20 / 10 \mu \mathrm{g}$ amoxicillin-clavulanate disks at a distance of $20 \mathrm{~mm}$ from ceftazidime disk

- Invert the plate and incubate overnight at $35^{\circ} \mathrm{C}$

iii. Plate reading and interpretation

- After overnight incubation, examine the plate for any obvious blunting or flattening of the zone of inhibition between the ceftazidime disk and the inducing substrates (imipenem, cefoxitin and amoxicillin-clavulanate disk)

- If there is any blunting or flattening of the zone, consider as a positive result for $A m p C$ production [Figure 4].

\section{Multiplex polymerase chain reaction for plasmid mediated AmpC genes}

Phenotypic tests do not differentiate between chromosomal and plasmid mediated $A m p C \beta$-lactamases. Plasmid-mediated $A m p C \beta$-lactamases are most accurately detected with the multiplex $A m p C$ PCR test.

\section{Preparation of template deoxyribonucleic acid (DNA)}

i. Requirements

- Test organism

- Molecular biology grade water

- Microcentrifuge tubes

- Absolute ethanol

- DNA extraction kit

ii. Procedure

- Inoculate a single colony of each organism into $5 \mathrm{ml}$ of Luria-Bertani broth and incubate for $20 \mathrm{~h}$

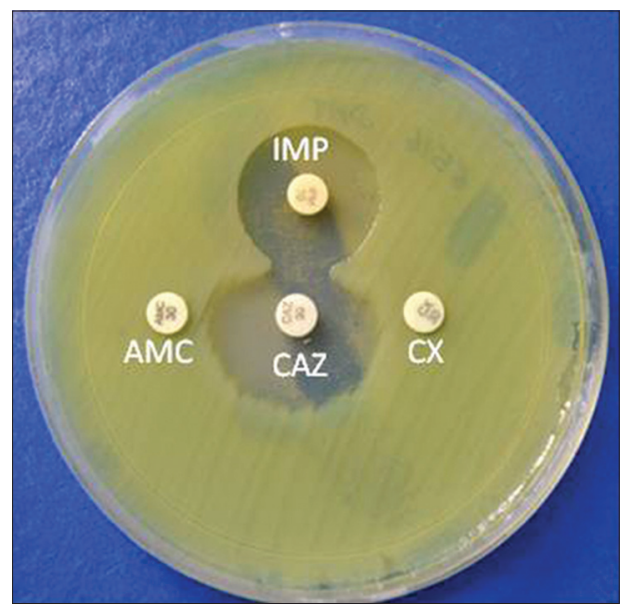

Figure 4: Representation of disk approximation test. Flattening of zone of ceftazidime toward imipenem disk (inducing substrate) showing positive result. IMP: Imipenem $(10 \mu \mathrm{g})$, CAZ: Ceftazidime $(10 \mu \mathrm{g})$, AMC: Amoxillin-clavulanate $(20 / 10 \mu \mathrm{g})$

at $37^{\circ} \mathrm{C}$ with shaking

- Harvest cells from $1.5 \mathrm{ml}$ of the overnight culture by centrifugation at $10,000 \times g$ for $5 \mathrm{~min}$

- Discard supernatant, re-suspend the pellet in 500 $\mu \mathrm{l}$ of distilled water

- Extract total DNA by using DNA extraction kit according to manufacturer's instructions

- Quantify total DNA prior to the multiplex PCR using spectrophotometer

Multiplex PCR

i. Requirements

- $\quad 0.5$-ml thin-walled PCR tubes

- Molecular biology grade water

- Taq DNA polymerase $(5 \mathrm{U} / \mu \mathrm{l})$

- 10X Taq buffer with KCL

- $\quad$ Tris- $\mathrm{HCl}(\mathrm{pH}$ 8.4)

- $25 \mathrm{mM} \mathrm{MgCl}_{2}$

- DNTP $_{\mathrm{S}} 10 \mathrm{Mm}$

ii. Procedure

- Make a master mix containing $20 \mathrm{mM}$ Tris- $\mathrm{HCl}$ (pH 8.4); $50 \mathrm{mM} \mathrm{KCl;} 0.2 \mathrm{mM}$ each dNTPs; $1.5 \mathrm{mM} \mathrm{MgCl} 2 ; 0.6 \mu \mathrm{M}$ primers MOXMF, MOXMR, CITMF, CITMR, DHAMF, and DHAMR; $0.5 \mu \mathrm{M}$ primers ACCMF, ACCMR, EBCMF, and EBCMR; $0.4 \mu \mathrm{M}$ primers FOXMF and FOXMR; and $1.25 \mathrm{U}$ of Taq DNA polymerase. Add $2 \mu \mathrm{lDNA}$ template. The list of all the primers are given in Table 3.

- Set the PCR program on an initial denaturation step at $94^{\circ} \mathrm{C}$ for $3 \mathrm{~min}$, followed by 25 cycles of DNA denaturation at $94^{\circ} \mathrm{C}$ for 30 s, primer annealing at $64^{\circ} \mathrm{C}$ for $30 \mathrm{~s}$, and primer extension at $72^{\circ} \mathrm{C}$ for $1 \mathrm{~min}$. After the last cycle, a final 


\begin{tabular}{|c|c|c|c|}
\hline Target (s) & Primer & Sequence ( $5^{\prime}$ to $\left.3^{\prime}\right)$ & $\begin{array}{c}\text { Expected } \\
\text { amplicon } \\
\text { size (bp) }\end{array}$ \\
\hline \multirow{2}{*}{$\begin{array}{l}\text { MOX-1, MOX-2, } \\
\text { CMY-1, CMY-8TO } \\
\text { CMY-11 }\end{array}$} & MOXMF & GCT GCT CAA GGA GCA CAG GAT & \multirow[t]{2}{*}{520} \\
\hline & MOXMAR & CAC ATT GAC ATA GGT GTG GTG C & \\
\hline \multirow{2}{*}{$\begin{array}{l}\text { LAT-1 TO LAT-4, } \\
\text { CMY-2 to CMY-7, } \\
\text { BIL-1 }\end{array}$} & CITMF & TGG CCA GAA CTG ACA GGC AAA & \multirow[t]{2}{*}{462} \\
\hline & CITMR & TTT CTC CTG AAC GTG GCT GGC & \\
\hline \multirow[t]{2}{*}{ DHA-1, DHA-2 } & DHAMF & AAC TTT CAC AGG TGT GCT GGG T & \multirow[t]{2}{*}{405} \\
\hline & DHAMR & CCG TAC GCA TAC TGG CTT TGC & \\
\hline \multirow[t]{2}{*}{$\mathrm{ACC}$} & ACCMF & AAC AGC CTC AGC AGC CGG TTA & \multirow[t]{2}{*}{346} \\
\hline & ACCMR & TTC GCC GCA ATC ATC CCT AGC & \\
\hline \multirow[t]{2}{*}{ MIR-1TACT-1 } & EBCMF & TCG GTA AAG CCG ATG TTG CGG & \multirow[t]{2}{*}{302} \\
\hline & EBCMR & CTT CCA CTG CGG CTG CCA GTT & \\
\hline \multirow[t]{2}{*}{ FOX-1 TO FOX-5B } & FOXMF & AAC ATG GGG TAT CAG GGA GAT G & \multirow[t]{2}{*}{190} \\
\hline & FOXMR & CAA AGC GCG TAA CCG GAT TGG & \\
\hline
\end{tabular}

extension step at $72^{\circ} \mathrm{C}$ for $7 \mathrm{~min}$

- Set the tube in the PCR machine and run the program.

\section{Electrophoresis}

i. Requirements

- Agarose

- Ethidium bromide

- Loading die

- 100-bp DNA ladder

ii. Procedure

- $\quad$ Prepare 2\% agarose gel in $1 \mathrm{X}$ TE buffer

- Analyze $5 \mu \mathrm{l}$ PCR product mixed with $1 \mu \mathrm{l}$ 6X loading die

- Use 100-bp DNA ladder as a marker

- $\quad$ Stain gel with ethidium bromide $(10 \mu \mathrm{g} / \mathrm{ml})$ and analyze the presence of bands in ultraviolet transilluminator

- Use the PCR mixtures with the addition of water in place of template DNA as negative control.

\section{Plate disposal}

- Keep all culture plates sealed inside blue plastic bags and seal in an autoclave bag

- $\quad$ Autoclave at $121^{\circ} \mathrm{C}$ for $30 \mathrm{~min}$

- Discard the sealed sterilized bags in the site designed for this purpose.

\section{ACKNOWLEDGMENT}

We acknowledge the financial support of ICMR for the performance of this study.

\section{REFERENCES}

1. Kaurthe J. Increasing antimicrobial resistance and narrowing therapeutics in typhoidal salmonellae. J Clin Diagn Res 2013;7:576-9.

2. Laxminarayan R, Klugman KP. Communicating trends in resistance using a drug resistance index. BMJ Open 2011;1:e000135.

3. Drawz SM, Bonomo RA. Three decades of beta-lactamase inhibitors. Clin Microbiol Rev 2010;23:160-201.

4. Hanson ND. AmpC beta-lactamases: What do we need to know for the future? J Antimicrob Chemother 2003;52:2-4.

5. Pérez-Pérez FJ, Hanson ND. Detection of plasmid-mediated $A m p C$ beta-lactamase genes in clinical isolates by using multiplex PCR. J Clin Microbiol 2002;40:2153-62.

6. Papanicolaou GA, Medeiros AA, Jacoby GA. Novel plasmid-mediated beta-lactamase (MIR-1) conferring resistance to oxyimino-and alpha-methoxy beta-lactams in clinical isolates of Klebsiella pneumoniae. Antimicrob Agents Chemother 1990;34:2200-9.

7. Mirelis B, Rivera A, Miró E, Mesa RJ, Navarro F, Coll P. A simple phenotypic method for differentiation between acquired and chromosomal AmpC beta-lactamases in Escherichia coli. Enferm Infecc Microbiol Clin 2006;24:370-2.

8. Handa D, Pandey A, Asthana AK, Rawat A, Handa S, Thakuria B. Evaluation of phenotypic tests for the detection of $A m p C$ beta-lactamase in clinical isolates of Escherichia coli. Indian J Pathol Microbiol 2013;56:135-8.

9. Performance Standards for Antimicrobial Susceptibility Testing, $20^{\text {th }}$ Informational Supplement. M100-S 21. Wayne, PA: Clinical and Laboratory Standards Institute; 2010.

10. Thomson KS. Extended-spectrum-beta-lactamase, $A m p C$, and Carbapenemase issues. J Clin Microbiol 2010;48:1019-25

How to cite this article: Gupta G, Tak V, Mathur P. Detection of AmpC $\beta$ lactamases in gram-negative bacteria. J Lab Physicians 2014;6:1-6. Source of Support: We acknowledge the financial support of ICMR for the performance of this study. Conflict of Interest: None declared. 